\title{
Environmental intervention for house dust mite control in childhood bronchial asthma
}

\author{
Engy M. El-Ghitany • Magda M. Abd El-Salam
}

Received: 25 October 2011/Accepted: 29 December 2011/Published online: 3 February 2012

(c) The Japanese Society for Hygiene 2012

\begin{abstract}
Objectives This study was carried out to determine the effectiveness of physical and chemical environmental control measures for house dust mites (HDM) in controlling bronchial asthma in children.

Methods A total of 160 asthmatic children who were sensitized to HDM underwent clinical and environmental assessment. The children were randomly allocated into one of four groups according to the intervention (chemical, physical, both chemical and physical, none) and the effectiveness of the intervention was assessed at 8 and 16 weeks.

Results The group for which physical control measures were used showed significant improvement in all outcome measures, including mean differences of forced expiratory volume after $1 \mathrm{~s}$ (FEV1) and peak expiratory flow rate (PEFR), which were $2.05 \%$ and $4.65 \mathrm{l} / \mathrm{min}$, respectively, at the 8 -week follow-up evaluation. The percentage of severe asthma decreased from 45 to $22 \%$. Similar results were obtained for the group with both chemical (tannic acid) and physical interventions ( $p<0.05$ for all measures). In the
\end{abstract}

\section{E. M. El-Ghitany $(\bowtie)$}

Tropical Health Department, High Institute of Public Health, Alexandria University, 165 El Horreya Avenue, Alexandria, Egypt

e-mail: ingy.elghitany@gmail.com

\section{M. Abd El-Salam}

Environmental Chemistry and Biology, Environmental Health Department, High Institute of Public Health, Alexandria University, Alexandria, Egypt

M. M. Abd El-Salam

Public Health Sciences, Biology Department, College of Science and Humanities Studies, Salman Bin Abdulaziz University, Al-Kharj, Al-Riyadh, Kingdom of Saudi Arabia group where tannic acid was used as a chemical measure, the number of children with moderate and severe asthma decreased from 15 in each category to 11 and 7, respectively. In the control group, only the mean difference of PEFR (1.62 1/min) was significant after 16 weeks. Despite these promising findings, only the FEV1 was significantly different $(p=0.014)$ when the four groups were compared. Conclusions Based on these results, we conclude that simple physical control measures have the potential to contribute to the control of asthma symptoms in asthmatic children sensitized to HDM allergen.

Keywords House dust mite - Asthma - Children . Environmental intervention $\cdot$ Control

\section{Introduction}

Bronchial asthma is a chronic inflammatory disease affecting 300 million individuals worldwide and causing 15 million disability-adjusted life years (DALYs) [1]. Although the global prevalence shows a wide range, namely, from 1 to $18 \%$, the differences between countries and regions are lessening, with an increasing prevalence in Africa, Latin America and parts of Asia [2]. During the last two decades, the prevalence of bronchial asthma has reached epidemic levels in some areas and populations, particularly in children living under highly urbanized conditions [3, 4]. Bronchial asthma is more likely to be found in the urban setting rather than in rural communities due to risk factors associated with modernization and the increased amount of time spent indoors. Few studies have been conducted in Egypt to measure asthma prevalence in children, but based on available data, the prevalence ranges from 3.25 to $9.4 \%$ [5-9]. The risks beyond the development of asthma 
are still a matter of debate and involve the interaction between different genetic and environmental factors. Several studies that have been carried out in different communities over the world have established sensitization to indoor allergens, especially house dust mites (HDM), as a major risk factor for asthma development and severity [10]. HDM are particularly ubiquitous in temperate and high humidity climates, both conditions which are met in Egypt. Several physical and chemical control measures for HDM have been described [11-14]. However, while most studies evaluating the environmental control measures showed a significant reduction in the allergen doses, their clinical effectiveness remains a matter of controversy [15-19]. Therefore, the aim of this study was to determine the effectiveness of physical and chemical environmental control measures for HDM in controlling asthma in asthmatic children who are sensitized to HDM.

\section{Patients and methods}

Study setting and design

The procedures of the study were approved by the Ethics Committee of the High Institute of Public Health, Alexandria University, Egypt.

The study was done in two phases; a cross-sectional study followed by a randomized controlled trial phase. The study cohort comprised 160 children, aged 5 to 12 years, who were attending the chest department of the general and teaching hospital (National Medical Institute) located in Damanhour City, El-Beheira Governorate, Egypt. The study was conducted for 1 year, commencing in January 2010. The cases were recruited throughout the first 8 months of the study (Fig. 1). All of the participants were diagnosed as having bronchial asthma by a physician at the

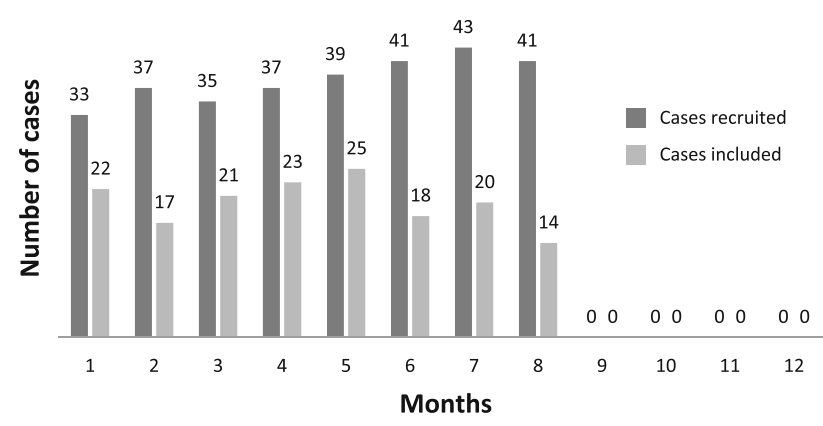

Fig. 1 The number of pediatric patients recruited and included monthly in the study during the study period [January (1) to December (12) 2010]. Patients diagnosed with bronchial asthma were recruited during the first 8 months of the study $(1-8)$, following which no cases were included. The last 4-month period of 2010 (9-12) was the follow-up period time of recruitment according to the Global Initiative for Asthma (GINA) guidelines, 2009 [11] and had been prescribed asthma treatment at some time during the preceding 6 months.

Informed written consent was obtained from each participant's parent(s) or caregiver and the child's assent was also obtained. All of the included children showed a positive skin test to HDM (Dermatophagoides pteronyssinus; $10,000 \mathrm{AU} / \mathrm{ml})$. A response was considered positive if the resulting wheel diameter after 15 min exceeded that caused by normal saline by $\geq 3 \mathrm{~mm}$ [20].

\section{Data collection}

Baseline clinical and environmental assessments of each patient were conducted through an interview using a predesigned questionnaire, physical examination, including respiratory function measurements, and a baseline home visit. The questionnaire included information relevant to socio-demographic data and behavioural and environmental conditions. By means of spirometry, peak expiratory flow rate (PEFR) and forced expiratory volume after $1 \mathrm{~s}$ (FEV1) were measured, with the best of three attempts recorded.

The children were classified according to the severity of their asthma [2] into having intermittent or persistent mild, moderate or severe asthma, respectively. This classification depends upon the frequency of symptoms/week, nighttime awakenings, $\beta_{2}$ agonist use for symptom control, interference with normal activity, including school attendance, and lung function. The percentage of uncontrolled asthma events according to the criteria set by the National Asthma Education and Prevention Programme [21] was also calculated. Controlled asthma patients should experience no or minimal symptoms (including at night), have no limitations on their activities (including physical exercise), have no (or minimal) requirement for rescue medications, have near-normal lung function, and experience only very infrequent exacerbations.

The baseline home visit occurred during the week following the interview as a means to evaluate the home environment. To this end, the interviewer completed a predesigned observational sheet that included questions on ventilation, furnishings, the child's bedding and housecleaning practices. Humidity and temperature were measured and recorded. Dust was collected from the child's bedroom (carpets, bedding and mattress) during this visit using a standardized protocol (vacuuming for 1 min over a $1-\mathrm{m}^{2}$ surface area using a $1,000 \mathrm{~W}$ cleaner with filter bags). After vacuuming, the filter was removed and placed in a sealable plastic bag.

Dust was quantitatively tested for Der p1 (protein with cysteine protease activity; [22]) using an enzyme-linked 
immunosorbent assay. The allergen level was expressed as micrograms per gram dust $\left(\mu \mathrm{g} \mathrm{g}^{-1}\right)$.

\section{Environmental intervention}

Through block randomization [23] using random sequences of block sizes, the children were randomly allocated into one of four groups according to recommended HDM control measures:

Group A: recommended physical methods were used to modify the environment of the child [24]. These included proper ventilation practice; completely encasing mattresses and pillows; washing the bedding weekly with hot water and detergents; vacuuming the living room and bedroom vacuum at least twice a week; washing or refrigerating soft and furry toys once a week, or excluding them from the bedrooms; removing carpets or vacuuming them more than once weekly; no pets.

Group B: tannic acid 3\% was provided as a chemical control measure to be used twice weekly for spraying the carpets and beddings.

Group C: both the physical and chemical methods described above were used.

Group D: a control group. No HDM control measures were implemented, and normal daily activities and living conditions were the same as those prior to enrollment in the study.

The approach used for intervention was based on the social cognitive theory $[25,26]$. The goal of the intervention was to educate the mother or the caregiver on the importance of each individual behaviour. As a first step, the targeted behaviour was modelled. The caregiver was then asked to perform the same mitigation behaviour while the counsellor provided feedback and encouragement with tips on basic knowledge and skills as well as motivation to continue to practice the desired environmental remediation.

Parents or caregivers were asked to record the daily outcome measures in a provided checklist sheet.

The children in all groups were evaluated twice 8 weeks apart by means of morning home visits. During the followup home visits, PEFR and FEV1 were measured (with the best of three attempts recorded) and the symptoms sheets were collected. The individual making the home visit was blinded to intervention group. Home visits at 2-week intervals were made by a second individual as a means to provide support and motivation regarding the intervention tailored to each group and to replenish tannic acid supplies (Groups B and C).
The following clinical outcome measures were re-evaluated in all children at 8 and 16 weeks during the follow-up:

- Severity of asthma according to the classification used for baseline assessment [2];

- Percentage of uncontrolled asthma [21];

- Incidence of hospitalization;

- Changes in PEFR, FEV1 (as a percentage of predicted value) over the study period adjusted to the baseline measures.

During the last follow-up visit, a dust sample was obtained using the same protocol described earlier and stored at $4^{\circ} \mathrm{C}$ until tested. HDM levels were measured using the same method used at the baseline.

\section{Statistical analyses}

Data analyses were performed using the Statistical Package for Social Sciences (SPSS, Chicago, IL). Proportions were compared by the chi-square test or Fisher's exact test in the event of small numbers. The McNemar and marginal homogeneity tests were used for paired categorical data. Normally distributed quantitative data are presented as mean values and standard deviations and compared by Student's $t$ test or analysis of variance. For non-parametric data, median and interquartile ranges were calculated and compared using the Mann-Whitney and Wilcoxon tests for comparing pre- and post-test data, or the Kruskal-Wallis test for comparing the four groups. Statistical significance was accepted at the 5\% level.

\section{Results}

A total of 306 children were initially eligible for enrollment in the study. The skin prick test was negative or doubtful in 104 children and 11 declined to participate. In addition, 31 children whose families did not have a vacuum cleaner were excluded as a vacuum cleaner was considered to be essential. The final number of participants was therefore 160 children.

The average age of the study cohort was 7.69 years (range 5-12 years), and 56.2\% were male. No significant differences were observed among the four intervention groups in terms of basic socio-demographic data and risk behaviours known to induce asthma (Tables 1, 2). The concentrations of HDM did not differ between the four intervention groups $(p=0.335)$ at the start of the study. We measured both the clinical outcomes of HDM control and post-intervention HDM loads. The four intervention groups were similar in terms of the parameters used for clinical asthma evaluation (Table 1), including the percentage of children suffering from uncontrolled asthma ( $p=0.893)$, which constituted $42.5 \%$ of all children 
Table 1 Baseline demographic and clinical characteristics of the study participants

\begin{tabular}{|c|c|c|c|c|c|}
\hline Variable $^{\mathrm{a}}$ & $\begin{array}{l}\text { Group A } \\
(n=40)\end{array}$ & $\begin{array}{l}\text { Group B } \\
(n=40)\end{array}$ & $\begin{array}{l}\text { Group C } \\
(n=40)\end{array}$ & $\begin{array}{l}\text { Group D } \\
(n=40)\end{array}$ & $p$ value \\
\hline Mean age, months (SD) & $83.80(15.87)$ & $86.65(15.06)$ & $92(17.60)$ & $90.70(16.08)$ & 0.1 \\
\hline Male & $22(55 \%)$ & $22(55 \%)$ & $26(65 \%)$ & $20(50 \%)$ & 0.89 \\
\hline Mean number of siblings (SD) & $2.45(1.43)$ & $2.80(1.32)$ & $3.35(1.3)$ & $1.90(0.97)$ & 0 \\
\hline First in birth order & $20(50 \%)$ & $16(40 \%)$ & $12(30 \%)$ & $12(30 \%)$ & 0.2 \\
\hline Frequent deferral from regular activities due to asthma & $6(15 \%)$ & $5(12.5 \%)$ & $7(17.5 \%)$ & $8(20 \%)$ & 0.82 \\
\hline Illiterate mother & $6(15 \%)$ & $4(10 \%)$ & $4(10 \%)$ & $20(50 \%)$ & 0.63 \\
\hline Illiterate father & $8(20 \%)$ & $5(12.5 \%)$ & $6(15 \%)$ & $5(12.5 \%)$ & 0.84 \\
\hline Non-working mother & $28(70 \%)$ & $24(60 \%)$ & $32(80 \%)$ & $12(30 \%)$ & 0.52 \\
\hline Non-working father & $18(45 \%)$ & $18(45 \%)$ & $24(60 \%)$ & $17(42.5 \%)$ & 0.38 \\
\hline Urban residence & $13(32.5 \%)$ & $19(47.5 \%)$ & $12(30 \%)$ & $20(50 \%)$ & 0.16 \\
\hline Mean monthly income per household, pounds (SD) & $165(41.8)$ & $156(46.2)$ & $161(43.2)$ & $158(39.6)$ & 0.89 \\
\hline Lack of access to infrastructure & $6(15 \%)$ & $4(10 \%)$ & $5(12.5 \%)$ & $5(12.5 \%)$ & 0.93 \\
\hline Mean age of asthma onset (SD) & $29.80(13.70)$ & $30.80(12.66)$ & $25.20(10.18)$ & $27.35(12.94)$ & 0.18 \\
\hline Frequency of attacks/year, mean (SD) & $10.25(9.36)$ & $9.2(11.15)$ & $13.35(9.70)$ & $10.15(8.97)$ & 0.25 \\
\hline Mean duration of attacks in hours (SD) & $4.93(1.81)$ & $4.89(2.03)$ & $5.85(1.72)$ & $5.35(2.27)$ & 0.11 \\
\hline Mean number of hospitalization in the last 2 months (SD) & $1.35(0.75)$ & $1.55(0.95)$ & $1.18(0.89)$ & $1.45(0.93)$ & 0.21 \\
\hline FEV1 ( $\%$ of predicted value) & $83.13(3.73 \%)$ & $83.7(2.86 \%)$ & $84.42(3.99 \%)$ & $85.05(3.98 \%)$ & 0.12 \\
\hline Mean PEFR, 1/min (SD) & $208.27(4.9)$ & $207.72(5.7)$ & $206.67(4.73)$ & $206.35(4.94)$ & 0.3 \\
\hline On maintenance treatment & $15(37.50 \%)$ & $17(42.5 \%)$ & $18(45 \%)$ & $18(45 \%)$ & 0.89 \\
\hline Family history of asthma & $32(80 \%)$ & $27(67.5 \%)$ & $33(82.5 \%)$ & $25(62.5 \%)$ & 0.13 \\
\hline
\end{tabular}

$S D$ Standard deviation, PEFR peak expiratory flow rate, FEVI forced expiratory volume after $1 \mathrm{~s}$

${ }^{a}$ Unless indicated otherwise, data are presented as the number $(n)$ of children, with the percentage given in parenthesis

Table 2 Baseline environmental and behavioural characteristics of the study participants

\begin{tabular}{|c|c|c|c|c|c|}
\hline Variable $^{\mathrm{a}}$ & Group A $(n=40)$ & Group B $(n=40)$ & Group C $(n=40)$ & Group D $(n=40)$ & $p$ value \\
\hline Mean age of residence building in years (SD) & $8.75(6.70)$ & $8.75(7.86)$ & $5.85(1.72)$ & $5.35(2.27)$ & 0 \\
\hline Presence of pets & $18(45 \%)$ & $15(37.5 \%)$ & $20(50 \%)$ & $19(47.5 \%)$ & 0.71 \\
\hline Passive smoking ${ }^{\mathrm{b}}$ & $12(30 \%)$ & $18(45 \%)$ & $19(47.5 \%)$ & $12(30 \%)$ & 0.21 \\
\hline Playing with furry toys & $17(42.5 \%)$ & $10(25 \%)$ & $15(37.5 \%)$ & $10(25 \%)$ & 0.06 \\
\hline Mean temperature, ${ }^{\circ} \mathrm{C}(\mathrm{SD})$ & $20.35(2.32)$ & $19.95(3.22)$ & $19.2(2.85)$ & $19.55(2.74)$ & 0.29 \\
\hline Mean humidity percentage (SD) & $74.20(9.26)$ & $77(10.91)$ & $76.5(11.51)$ & $75.15(11.80)$ & 0.65 \\
\hline Adequate natural ventilation & $24(60 \%)$ & $16(40 \%)$ & $19(47.5 \%)$ & $10(25 \%)$ & 0.07 \\
\hline Presence of fans & $2(5 \%)$ & $4(10 \%)$ & $6(15 \%)$ & $0(0 \%)$ & 0.59 \\
\hline Carpets or rugs & $32(80 \%)$ & $28(70 \%)$ & $32(80 \%)$ & $36(90 \%)$ & 0.57 \\
\hline Mean age of pillows and mattresses, years (SD) & $3.23(2.83)$ & $3.39(2.07)$ & $4.3(2.38)$ & $3.7(2.12)$ & 0.18 \\
\hline Complete covering of beddings & $12(30 \%)$ & $18(45 \%)$ & $12(30 \%)$ & $18(45 \%)$ & 0.28 \\
\hline Frequent use of nylon cover & $12(30 \%)$ & $13(32.5 \%)$ & $10(25 \%)$ & $10(25 \%)$ & 0.84 \\
\hline Use of impermeable cover & $6(15 \%)$ & $4(10 \%)$ & $4(10 \%)$ & $2(7.5 \%)$ & 0.16 \\
\hline At least weekly sun exposure of beddings & $14(35 \%)$ & $16(40 \%)$ & $13(32.5 \%)$ & $15(37.5 \%)$ & 0.91 \\
\hline Mean Der $\mathrm{p} 1$ concentration, $\mu \mathrm{g} \mathrm{g}^{-1}$ (SD) & $7.32(0.72)$ & $6.5(0.81)$ & $6.64(0.84)$ & $6.44(0.78)$ & 0.34 \\
\hline
\end{tabular}

Der $\mathrm{p} 1$, protein with cysteine protease activity

${ }^{a}$ Unless indicated otherwise, data are presented as the number $(n)$ of children, with the percentage given in parenthesis

b Passive smoking was considered if any of the households was a smoker. None of the participants were smokers

$(19,16,16$ and $17 \%$ of children in groups A, B, C and D, respectively). Moreover, none of the features that are suggestive of an increased risk of adverse events in the future, including poor clinical control, frequent exacerbation in the last year, admission to critical care for asthma at any time in the past, low FEV1, exposure to cigarette 
Table 3 Levels of house dust mites in the four groups 16 weeks after introduction of the intervention

\begin{tabular}{lllll}
\hline Variable & $\begin{array}{l}\text { Group A } \\
(n=40)\end{array}$ & $\begin{array}{l}\text { Group B } \\
(n=40)\end{array}$ & $\begin{array}{l}\text { Group C } \\
(n=40)\end{array}$ & $\begin{array}{l}\text { Group D } \\
(n=40)\end{array}$ \\
\hline $\begin{array}{l}\text { Mean Der p1 } \\
\text { concentration in } \\
\mu \mathrm{g} \mathrm{g}^{-1}\end{array}$ & 6.17 & 6.21 & 5.97 & 6.28 \\
$\begin{array}{l}\text { Standard deviation } \\
p \text { value }\end{array}$ & 0.61 & 0.65 & 0.71 & 0.67 \\
\hline
\end{tabular}

The results for each group were compared to the original baseline level shown in Table 2

smoke and high dose medications, were significantly different statistically.

Although the mean levels of HDM had improved in all groups (Table 3), the highest significant results were found for children in groups $\mathrm{A}$ and $\mathrm{C}$. The change in group $\mathrm{D}$ was not statistically significant.

In group $\mathrm{A}$, the baseline distribution of asthma severity classes was $7.5,17.5,30$, and $45 \%$ of children with intermittent, mild persistent, moderate persistent, and severe persistent asthma, respectively. This distribution changed significantly $(p=0.000)$ at 16 weeks after implementation of the physical control measures, with the frequencies of intermittent and mild persistent asthma increasing to 17.5 and $35 \%$ of children, respectively, while those of moderate and persistent asthma decreasing to 25 and $22.5 \%$ of children, respectively. Moreover, the frequency of uncontrolled asthma among the children was $25 \%$, which was significantly lower than that at baseline. There was a similar significant reduction $(p=0.000)$ in the median number of hospitalizations at the 8- and 16-week follow-up. FEV1 as a percentage of the predicted value and the PEFR $(1 / \mathrm{min})$ also improved significantly at the two follow-up time points, reaching $85.68 \pm 2.43$ and $215.09 \pm 5.2$, respectively, after 16 weeks. Although all of the outcome measures continued to improve between 8 and 16 weeks of follow-up, the changes were not statistically significant.

In group $\mathrm{B}$, the distribution of children according to asthma severity did not change significantly at the followup endpoint (16 weeks; $p=0.074$ ), but there were significant changes in other parameters, including the median number of days with hospitalization and the results of the lung function tests (Table 4). No significant changes were found at the 8-week follow-up, but FEV1 and PEFR had improved after 16 weeks, reaching $84.6 \pm 4.21 \%$ and $208.95 \pm 6.1 \mathrm{l} / \mathrm{min}$, respectively. In addition, the number of children satisfying the definition of uncontrolled asthma had insignificantly decreased from 16 to 13 .

In group $\mathrm{C}$, the asthma score improved significantly, with the frequency of children with mild and intermittent asthma increasing from 17.5 and $12.5 \%$ to 47.5 and $22.5 \%$, respectively, and that of children suffering from moderate

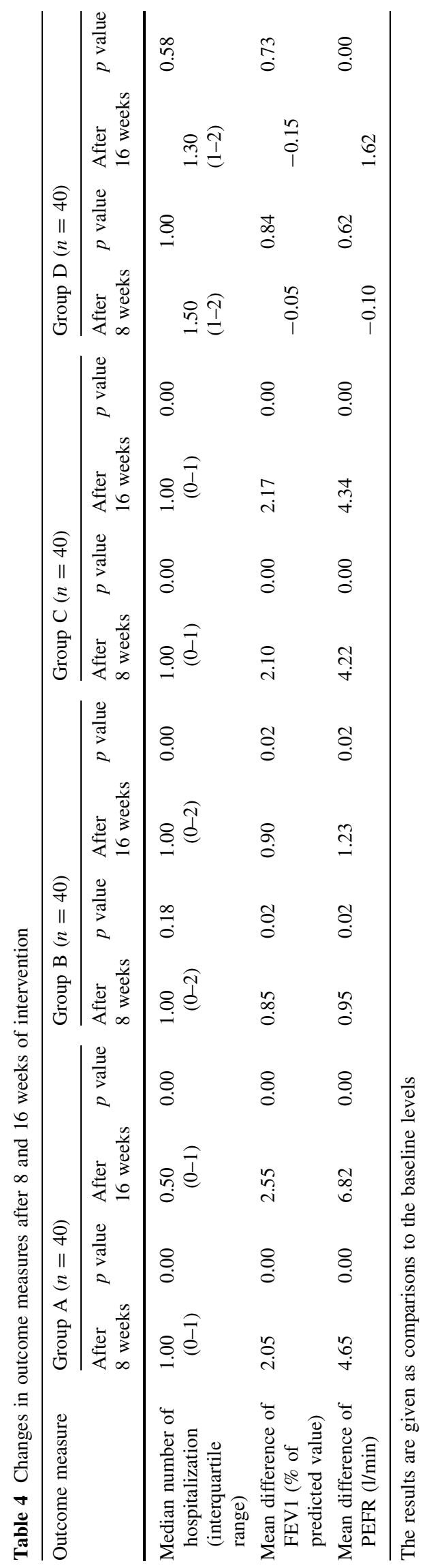


(30\%) and severe (40\%) asthma decreasing to 20 and $10 \%$, respectively. The results for group $\mathrm{C}$ were similar to those fore group $\mathrm{A}$ in terms of the decreased number of children with uncontrolled asthma, the median number of hospitalizations, FEV1 and PEFR (Table 4). The mean values of FEV1 and PEFR at the end of intervention were $86.59 \pm 3.7 \%$ and $211.01 \pm 4.53 \mathrm{l} / \mathrm{min}$, respectively.

Although there was a reduction in the number of children having severe asthma (from 16 to 7 children) in the control group, neither the frequency nor the distribution of asthma severity (Tables 4,5 ) within the group showed any significant improvement. The only outcome measure that showed significant improvement was the PEFR after 16 weeks of follow-up (mean value $207.97 \pm 4.43$; Table 4 ). The mean value of FEV1 at the end of the 16th week was nearly the same as that of that at baseline $(84.9 \pm 4.31 \%)$.

A comparison of the four groups revealed that the distribution of asthma severity (Table 5) and FEV1 levels (Table 4) were significantly different at the 16-week followup ( $p=0.046$ and 0.014 , respectively). However, no statistical differences were noted at the same time point for the number of days of hospitalization (Table 4) and PEFR levels.

\section{Discussion}

At the beginning of the study, the patients were assigned to one of the three active intervention groups or to a control group. At baseline, there were almost no significant differences between groups in terms of the severity of the clinical condition or the concentration of Der pl allergen. We also observed that poor environmental conditions and behavioural practices among the study participants favoured the presence and persistence of HDM, with no significant differences between groups. This lack of differences between groups and the close monitoring and remotivation with respect to the allocated control measures were crucial for further detection of significant changes after the intervention. The groups did vary significantly in other factors, such as number of siblings and age of residential buildings, but as neither of these factors have been given any importance in the literature on HDM and asthma, we did not believe they would bias our results, especially when the changes were also evaluated within the same group. Home visits were chosen over clinic interviews for several reasons: (1) to minimize the frequency of missed appointments; (2) to avoid any variations in time with respect to the follow-up points; (3) to be able to demonstrate (model) and train the household on the use of control measures and how to adapt them to their home situation; (4)y to ensure the highest compliance rate possible. The use of a medical indoor environment counsellor in such studies has been shown to significantly enhance the

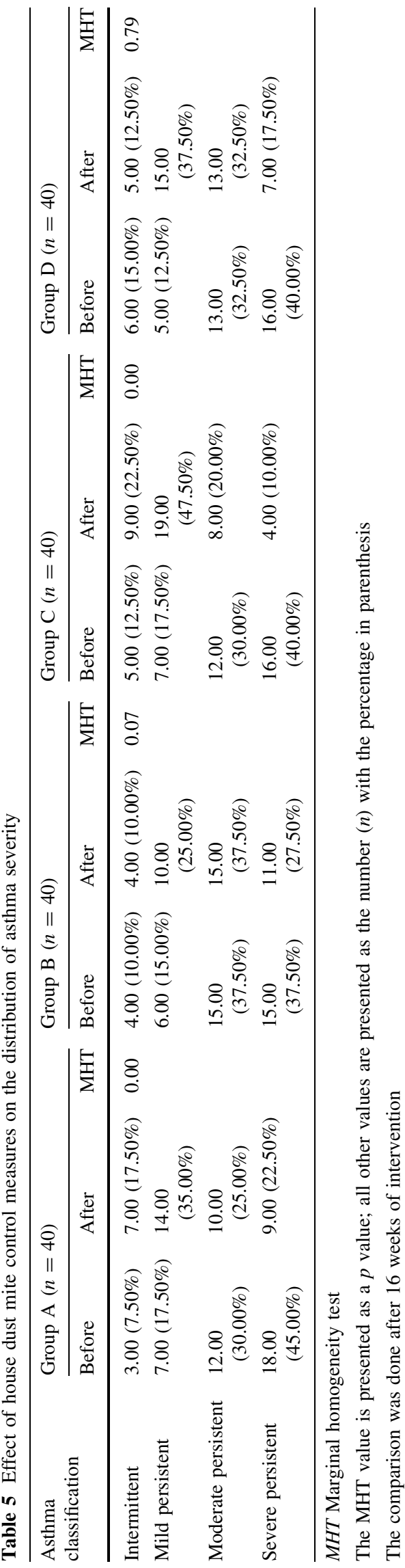


compliance when allergen avoidance measures are proposed [27]. The absence of this approach may explain the negative results in some mite avoidance studies [28].

In group $\mathrm{A}$, for whom physical control measures were recommended, there was an observed improvement in all of the clinical outcomes by the end of the 8 weeks, which subsequently stabilized after 16 weeks. Quite similar results were observed among the children in group C. Several studies have examined the efficiency of a single or a combination of different HDM physical control measures for the eradication and/or improvement of the clinical and economic impact of asthma. Included in the single interventions that have resulted in a massive reduction in HDM load are intensive vacuuming of carpets [29] and the use of warm water and detergent at least twice weekly for washing beddings [30]. In a large randomized controlled double-blind trial, Woodcock et al. [18] found that the use of an impermeable mattress cover as a single intervention neither improved the clinical asthma symptoms nor reduced mite allergen level at 12 months, a finding which was further supported by Terreehorst et al. [31] and Dharmage et al. [32].

Most studies which have applied combined physical methods showed a reduction in the number of HDM and Der p1 concentration and/or an improvement in symptoms [33, 34]. Our findings are in agreement with these earlier findings.

In contrast, a meta-analysis of randomized trials that investigated the effect of physical or chemical measures to control mites on asthma patients found that none of the measures applied was as effective as a prophylactic treatment of asthma patients [35].

Although there was some improvement in the clinical outcomes of the patients in group B, this improvement was restricted to lung functions; the interventions in group B did not result in a significant reduction in the frequency of children with severe asthma. The improvement in lung function was only noticed after 16 weeks of follow-up. The chemical measures used in this study were meant to decrease the HDM concentration, while the physical ones were meant to limit exposure as well as minimize the concentration of HDM per unit dust.

The results observed for group D were similar to those for group B, with the children only showing a statistically relevant change at the end of the study in one of the respiratory functions (PEFR). Some studies have shown that PEFR is a far less sensitive marker than FEV1 for detecting a reaction [36-38]. This minor improvement could be attributed to the interview procedure, the use of clinical data sheets and home visits during which time attention may have been paid the attention to asthma care, including adherence to the usual medications and avoidance of arousing factors. In a study comparing a combined approach using physical barriers and an acaricidal wash [39], the combined approach was found to be effective in reducing HDM allergen concentrations in the bedding. However, HDM allergen levels remained high by international standards. However, in this study, the combined approach was also only compared to a control group - and not to groups using each approach alone [39]. As in our study, a slight reduction in the level of mite allergen on the carpets was achieved using $1 \%$ tannic acid for cleaning, but it did not appear to achieve a worthwhile clinical benefit in terms of the treatment of mite-sensitive patients or as the primary or secondary prophylaxis [40]. A 2004 Cochrane review did not recommend individual chemical and physical methods aimed at reducing exposure to HDM allergens [41], and a subsequent review in 2008 did not recommend them at all [42].

In this study, we assumed good compliance of the families, not only as self-reports but as also evidenced by the reduction of the HDM mean concentration levels in the intervention groups. Therefore, the significant clinical improvement observed in groups $\mathrm{A}$ and $\mathrm{C}$ can be attributed to the control measures applied. Based on the results of our study, we suggest that the improvement in group $\mathrm{C}$ is mainly due to the physical control measures.

In this study, $66 \%$ of the asthmatic children showed evidence of sensitivity to HDM allergen, a frequency which is close to that detected by Jung-Wook et al. in Korea [43]. Therefore, simple physical control measures aimed at HDM avoidance should be recommended for all families with children suffering from bronchial asthma in order to control the severity of asthma. In this study, researchers did not provide or suggest any expensive or poorly available control measures, such as high-efficiency particulate air (HEPA) vacuuming or bedding encasement with mite-blocking fibre. We recommended simple and realistic measures that could be easily applied not only during the study, but also throughout life, especially in communities with poor resources and a high illiteracy rate.

Acknowledgements We acknowledge all of the children and families who participated in the study as well as the staff members of the National Medical Institute who facilitated the recruitment of our cases. Special thanks go to Dr. Mohamed Talaat Omar, paediatrician at the National Medical Institute.

Conflict of interest None.

\section{References}

1. Masoli M, Fabian D, Holt S, Bealey R. The global burden of asthma: executive summary of the GINA Dissemination Committee report. Allergy. 2004;59(5):469-78.

2. Pearce N, Aït-Khaled N, Beasley R, Mallol J, Keil U, Mitchell E, et al. Worldwide trends in the prevalence of asthma symptoms: phase III of the International Study of Asthma and Allergies in Childhood (ISAAC). Thorax. 2007;62(9):758-66.

3. Kay AB. Allergy and allergic diseases. Second of two parts. N Engl J Med. 2001;344(2):109-13. Review. 
4. The National Institute of Health (NIH). Global initiative for asthma: global strategy for asthma management and prevention. NIH publication 2004 no. 02-3659. Bethesada: NIH

5. Khallaf N, el-Ansary S, Hassan M. Acute respiratory infections: sentinel survey in Egypt. National ARI Control Programme, Child Survival Project, Ministry of Health, Bab El Louk, Cairo, Egypt. 1993.

6. El-Hefny AM, Nassar SI, El-Heneidy FM, Said M, El-Beleidy AS, El-Marsam E, et al. Epidemiology of childhood asthma in Cairo. Med J Cairo Univ. 1994;62:505-18.

7. Georgy V, Fahim HI, El-Gaafary M. Prevalence and socioeconomic associations of asthma and allergic rhinitis in northern Africa. Eur Respir J. 2006;28:756-62.

8. Khedr MS. Epidemiology of asthma in Egypt. Paper presented at the Middle East Asthma Symposium, Cairo, Egypt: 1988.

9. Zedan M, Settin A, Farag M, Ezz-Elregal M, Osman E, Fouda A. Prevalence of bronchial asthma among Egyptian school children. Egypt J Bronchology. 2009;3:124-30.

10. Custovic A, Simpson A, Woodcock A. Importance of indoor allergens in the induction of allergy and elicitation of allergic disease. Allergy. 1998;53:115-20.

11. GINA (Global Initiative for Asthma). The global strategy for asthma management and prevention 2009. Available at: http:// www.ginasthma.org.

12. Peat $\mathrm{J}$, Bjforksten B. Primary and secondary prevention of allergic asthma. Eur Respir J. 1998;12(27):28s-34s.

13. Dietemann A, Bessot JC, Hoyet C, Ott M, Verot A, Pauli G. A double-blind, placebo-controlled trial of solidified benzyl benzoate applied in dwellings of asthmatic patients sensitive to mites: clinical efficacy and effect on mite allergens. J Allergy Clin Immunol. 1993;91:738-46.

14. Hayden ML, Rose G, Diduch KB, Domson P, Chapman MD, Heymann PW, et al. Benzyl benzoate moist powder: investigation of acarical activity in cultures and reduction of dust mite allergens in carpets. J Allergy Clin Immunol. 1992;89:536-45.

15. Carter MC, Perzanowski MS, Raymond A, Platts-Mills TA. Home intervention in the treatment of asthma among inner-city children. J Allergy Clin Immunol. 2001;108:732-7.

16. Gotzsche PC, Johansen HK, Burr ML, Hammarquist C. House dust mite control measures for asthma. Cochrane Database Syst Rev. 2001; 3:CD001187.

17. Htut T, Higenbottam TW, Gill GW, Darwin R, Anderson PB, Syed N. Eradication of house dust mite from homes of atopic asthmatic subjects: a double-blind trial. J Allergy Clin Immunol. 2001;107:55-60.

18. Woodcock A, Forster L, Matthews E, Martin J, Letley L, Vickers M. Control of exposure to mite allergen and allergen-impermeable bed covers for adults with asthma. N Engl J Med. 2003; 349:225-36.

19. Morgan WJ, Crain EF, Gruchalla RS, O'Connor GT, Kattan M, Evans CR, et al. Results of a home-based environmental intervention among urban children with asthma. $\mathrm{N}$ Engl $\mathrm{J}$ Med. 2004;351:1068-80.

20. American Academy of Allergy and Immunology. Skin testing and radioallergosorbent testing (RAST) for diagnosis of specific allergens responsible for IgE-mediated diseases. J Allergy Clin Immunol. 1983;72:515-7.

21. National Asthma Education and Prevention Program. National Asthma Education and Prevention Program Expert Panel Report 3-guidelines for the diagnosis and management of asthma, Summary Report 2007. J Allergy Clin Immunol. 2007;120(5):S94-138.

22. Hamilton RG, Eggleston PA. Environmental allergen analyses. Methods. 1997;13:53-60.

23. Matts J, Lachin J. Properties of permuted-block randomization in clinical trials. Control Clin Trials. 1988;9:327-44.
24. Crain EF, Walter M, O'Connor GT, Mitchell H, Gruchalla RS, Kattan M, et al. Home and allergic characteristics of children with asthma in seven US urban communities and design of an environmental intervention: the Inner-City Asthma Study. Environ Health Perspect. 2002;110:939-45.

25. Bandura A. Social foundations of thought and action: a social cognitive theory. Englewood Cliffs: Prentice-Hall; 1986.

26. Pajares F. Self-efficacy beliefs in academic settings. Rev Educ Res. 1996;66(4):543-78.

27. de Blay F, Fourgaut G, Hedelin G, Vervloet D, Michel FB, Godard P, et al. Medical Indoor Environment Counselor (MIEC): role in compliance with advice on mite allergen avoidance and on mite allergen exposure. Allergy. 2003;58(1):27-33.

28. Frederick JM, Warner JO, Jessop WJ, Enander I, Warner JA. Effect of a bed covering system in children with asthma and house dust mite hypersensitivity. Eur Respir J. 1997;10:361-6.

29. Causer SM, Lewis RD, Batek JM Sr, Ong KH. Influence of wear, pile height and cleaning method on removal of mite allergen from carpet. J Occup Environ Hyg. 2004;1:237-42.

30. Eggleston PA. Improving indoor environments: reducing allergen exposures. J Allergy Clin Immunol. 2005;116:122-6.

31. Terreehorst I, Duivenvoorden HJ, Tempels-Pavlica Z, Oosting AJ, de Monchy JG, Bruijnzeel-Koomen CA, et al. The effect of encasings on quality of life in adult house dust mite allergic patients with rhinitis, asthma and/or atopic dermatitis. Allergy. 2005;60(7):888-93.

32. Dharmage S, Walters EH, Thien F, Bailey M, Raven J, Wharton C, et al. Encasement of bedding does not improve asthma in atopic adult asthmatics. Int Arch Allergy Immunol. 2006;139:132-8.

33. Warner JA, Frederick JM, Bryant TN, Weich C, Raw GJ, Hunter $\mathrm{C}$, et al. Mechanical ventilation and high-efficiency vacuum cleaning: a combined strategy of mite and mite allergen reduction in the control of mite-sensitive asthma. J Allergy Clin Immunol. 2000;105(1 Pt 1):75-82.

34. Takaro TK, Wu F. Childhood asthma and environmental interventions. Environ Health Perspect. 2007;115(6):971-5.

35. Gotzsche PC, Hammarquist C, Burr M. House dust mite control measures in the management of asthma: meta-analysis. Br Med J. 1998;317:1105-10.

36. Meltzer AA, Smolensky MH, D’ Alonzo GE, Harrist RB, Scott PH. An assessment of peak expiratory flow as a surrogate measurement of FEV, in stable asthmatic children. Chest. 1989;96:329-33.

37. Murray AB, Ferguson AC. A comparison of spirometric messurements in allergen bronchial challenge testing. Clin Allergy. 1981;11:87-93.

38. Bérubé D, Cartier A, L'Archevêque J, Ghezzo H, Malo JL. Comparison of peak expiratory flow rate and FEV1 in assessing bronchomotor tone after challenges with occupational sensitizers. Chest. 1991;99:831-6.

39. Mihrshahi S, Marks GB, Criss S, Tovey ER, Vanlaar CH, Peat JK. CAPS Team. Effectiveness of an intervention to reduce house dust mite allergen levels in children's beds. Allergy. 2003;58(8):784-9.

40. Lau S, Wahn J, Schulz G, Sommerfeld C, Wahn U. Placebocontrolled study of the mite allergen-reducing effect of tannic acid plus benzyl benzoate on carpets in homes of children with house dust mite sensitization and asthma. Pediatr Allergy Immunol. 2002;13(1):31-6.

41. Gotzsche PC, Johansen HK, Schmidt LM, Burr ML. House dust mite control measures for asthma. Cochrane Database Syst Rev. 2004;3:CD001187.

42. Gotzsche PC, Johansen HK. House dust mite control measures for asthma. Cochrane Database Syst Rev. 2008;3:CD001187.

43. Jung-Wook S, Ju-Hee S, Tae-Won S, Kyung-Won K, Eun-Soo K, Myung HS, et al. Atopy and house dust mite sensitization as risk factors for asthma in children. Yonsei Med J. 2005;46(5):629-34. 